\title{
LITERATURA INFANTIL E EDUCAÇÃO AMBIENTAL: UMA BREVE DISCUSSÃO
}

\section{Ronaldo Desiderio Castange}

Universidade Estadual Paulista - FCT/UNESP, Mestrado em Educação, Presidente Prudente, SP. E-mail: castange@live.com

\section{RESUMO}

Discorremos sobre a possibilidade de desenvolvimento da Educação Ambiental a partir da literatura infantil. Como meio para isso utilizamos as estratégias de leitura, de maneira a garantir a leitura literária da obra, abrindo espaços para as discussões acerca das questões ambientais. Acreditamos que, desta forma, as crianças apreendam conceitos básicos para uma melhor compreensão e atuação no meio ambiente, ao mesmo tempo em que participam de uma atividade lúdica, onde também se desenvolve o gosto pela leitura e a habilidade leitora e de interpretação de texto. Percebemos que a atividade é bem aceita pelas crianças e os objetivos são facilmente alcançados, uma vez que agem como agentes multiplicadores, despertando o desejo da leitura em amigos e familiares e explanando as atitudes ambientalmente corretas para todos em seu entorno.

Palavras-chave: educação ambiental, literatura infantil, estratégias de leitura, livros, crianças.

\section{CHILDREN'S LITERATURE AND ENVIRONMENTAL EDUCATION: A BRIEF DISCUSSION}

\begin{abstract}
We discuss the possibility of development of environmental education from children's literature. As a means to this use reading strategies in order to ensure the literary reading of the work, thereby advancing discussions about environmental issues. We believe that in this way, children seize basics for a better understanding and action on the environment, while participating in a fun activity, which also develops a love of reading and reading and reading comprehension skills. We realized that the activity is well accepted by children and goals are easily achieved, since they act as multipliers, raising the reading desire in friends and family and explaining the environmentally correct attitudes for everyone around them.
\end{abstract}

Keywords: environmental education, children's literature, Reading strategies, book's, children's. 


\section{INTRODUÇÃO}

Ao pensarmos em crianças e em livros, nos vem à cabeça a ideia de leitura, trata-se de uma fase importante e delicada, onde se desenvolve a competência leitora e os principais estímulos para a fixação do habito leitor. Para tratar deste momento nos valemos das estratégias de leitura, que permitem melhor compreensão e aproveitamento do ato de ler por parte das crianças e favorece, ao abrir espaços de discussão, a inserção de temas como o do nosso interesse: a Educação Ambiental.

Sobre ela, Carvalho (2006, p. 52) explica que surge como "uma prática de conscientização capaz de chamar a atenção para a finitude e a má distribuição no acesso aos recursos naturais e envolver cidadãos em ações sociais ambientalmente apropriadas". Contudo, o autor alerta para o risco de uma visão simplista de educação ambiental:

Muitas vezes, as atividades em Educação Ambiental ensinam o que fazer e como fazer certo, transmitindo uma série de procedimentos ambientalmente corretos. Mas isso nem sempre garante a formação de uma atitude ecológica, isto é, de um sistema de valores sobre como relacionar-se com o ambiente (CARVALHO, 2006, p. 180).

Dessa forma nosso objetivo foi romper com a visão simplista sobre a Educação Ambiental, possibilitando a apreensão de conteúdos de forma significativa pelas crianças, a partir de livros de literatura infantil.

\section{METODOLOGIA}

Com o objetivo de demonstrar aquilo que acreditamos ser uma boa prática de educação ambiental, amparamo-nos de livros de literatura infantil e paradidáticos para realizar as atividades por meio das estratégias de leitura, incutindo os conteúdos relacionados à Educação Ambiental e finalizando com a confecção de objetos a partir de materiais recicláveis.

Visualizam-se os resultados observando o interesse e a participação das crianças em todas as fases da atividade e posterior multiplicação das informações apreendidas para amigos de outras salas e funcionários da escola.

\section{RESULTADOS}

Para exemplificar nossa pesquisa, um dos exemplos desenvolvidos com alunos do 60 ano, de uma escola particular de Presidente Prudente - SP, uniu dois livros infantis: "A festa no céu Angela Lago" e "Uma avenida na floresta - Bárbara V. de Carvalho". 
A leitura dos livros foi realizada de forma a privilegiar as histórias, dando ênfase às falas das personagens e a ilustração. Os momentos antes, durante e depois da leitura foram desenvolvidos, levantando as expectativas das crianças a partir no nome dos livros e da capa, questionamentos a partir do desenvolvimento das histórias, bem como atribuindo outros desfechos a partir da imaginação das crianças.

Como a intenção é desenvolver conteúdos relacionados à Educação Ambiental, após as atividades de leitura destes livros, levantou-se a questão de uma personagem específica: a coruja. Voltando nas histórias e verificando como a personagem aparece. Geralmente com pouca fala, observando, com "cara de inteligente", a partir da fala dos alunos, dando conselhos ou organizando situações.

Tendo observado esta personagem, levantaram-se então os conhecimentos prévios - uma das estratégias de leitura segundo Solé (1998) e Girotto e Silva (2010) - das crianças a respeito da coruja. "Alguém já viu alguma coruja?", “Onde elas costumam viver?”, “O que elas comem?”, "Pra que serve a coruja, afinal?", entrando na questão da importância deste animal para a manutenção dos ecossistemas, trabalhando conceitos referentes à cadeia alimentar, controle de populações, respeito às diferentes formas de vida, entre outros.

Após essa atividade de aquisição de conhecimentos, as crianças foram levadas a desenvolver suas próprias corujas com materiais recicláveis, sendo o principal o rolinho de papel higiênico. Com orientação do professor e coletivamente, construíram suas corujas e saíram pela escola explicando como as fizeram e o que aprenderam. Podemos visualizar na imagem 1, abaixo, o resultado deste trabalho:

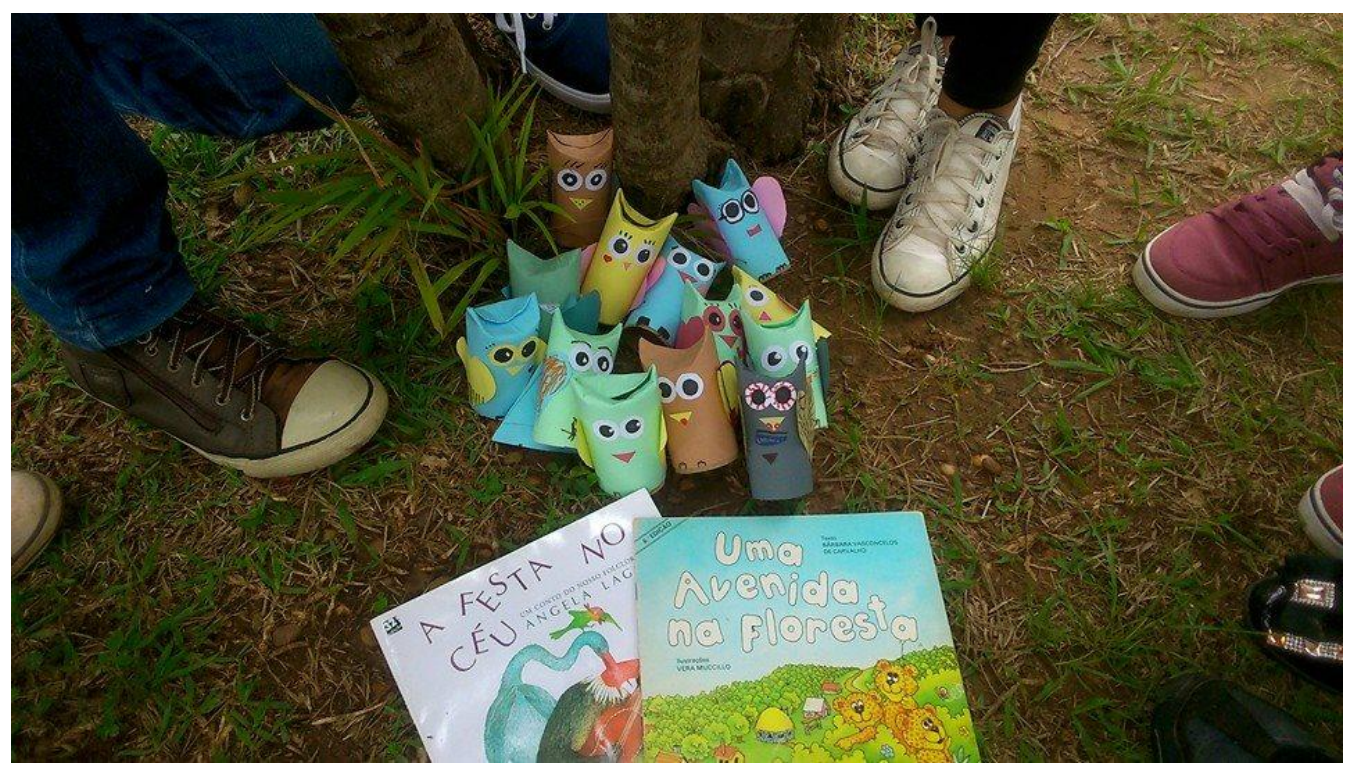

Imagem 1. Corujas confeccionadas pelos alunos, a partir da leitura dos livros, com o uso de materiais recicláveis . 
Outro exemplo deste tipo de atividade se deu com a mesma turma, desta vez com o livro paradidático chamado "O resgate da tartaruga - Guilherme Domenichelli".

Os livros paradidáticos possuem direcionamento para questões determinadas (PAIVA e OLIVEIRA, 2010), fato que os diferenciam dos livros de literatura, contudo, as etapas a serem desenvolvidas são as mesmas. Podemos realizar a leitura de forma literária e prazerosa do livro, abordando as expectativas das crianças sobre a história a partir do título e da capa do livro, chamando atenção para as personagens e ilustrações e discutindo sobre o desfecho da trama. Após a leitura do livro uma retomada pode ser feita atentando para os conceitos e conteúdos abordados, acrescentando novas informações.

Neste livro também levantamos os conhecimentos prévios dos alunos sobre a temática de preservação das tartarugas marinhas, abordando assuntos relacionados à preservação da vida aquática, problemas enfrentados no fundo do mar por vias da poluição, aumento das temperaturas e pesca irregular, a questão do ciclo de vida das tartarugas, ameaças à suas vidas, projetos de preservação da espécie, além de permitir o conhecimento de regiões distintas do planeta onde as tartarugas fazem sés trajetos ao longo do ano.

Novamente após as atividades de leitura e construção coletiva de conhecimentos novos as crianças fizeram uma dobradura da tartaruga e algumas delas enfeitaram e pintaram seus cascos, comentando sobre o trabalho e o que aprenderam por toda a escola.

Abaixo podemos ver, na imagem 2 , o resultado deste trabalho:

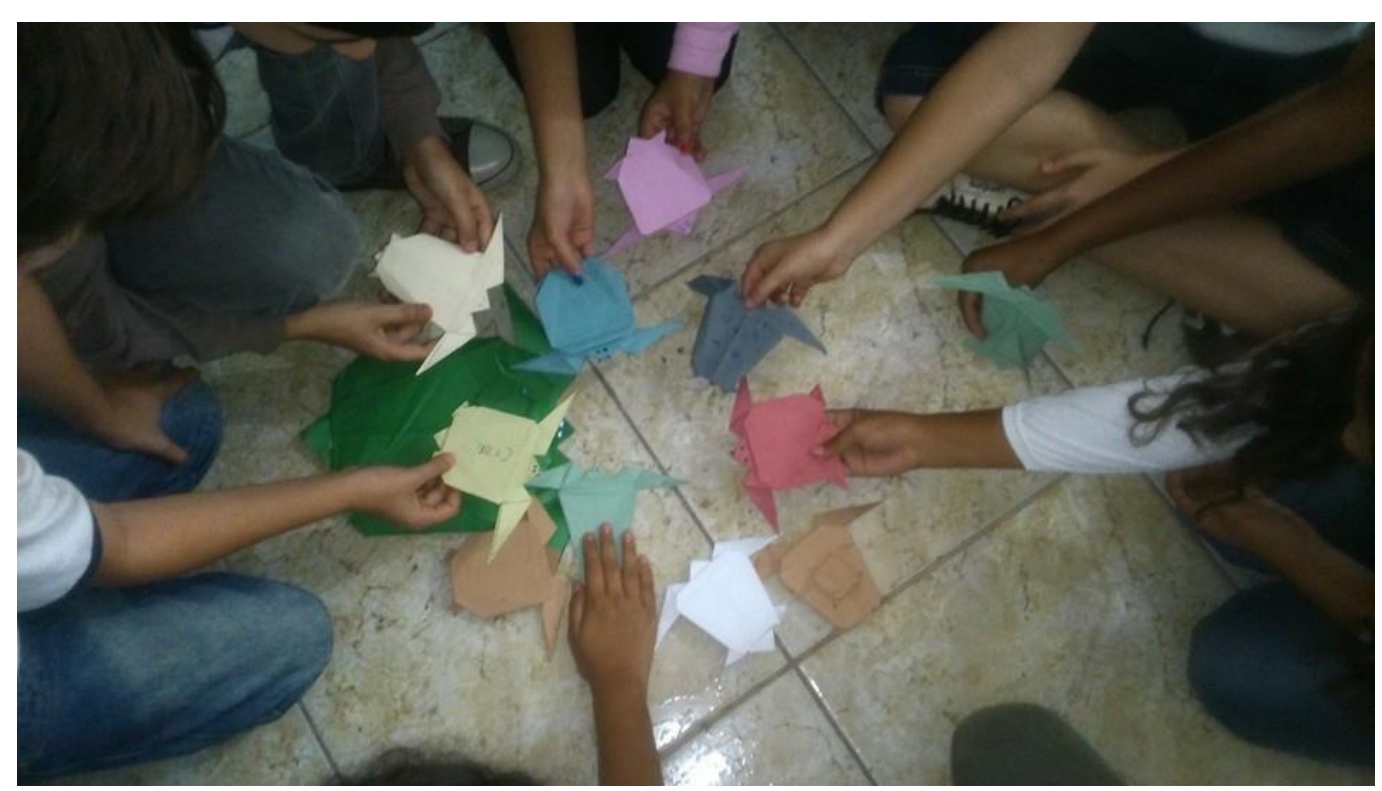

Imagem 2: Tartarugas confeccionadas pelos alunos, a partir da leitura dos livros, om o uso de materiais recicláveis. 


\section{DISCUSSÃO}

Para permitir um desenvolvimento positivo da atividade envolvendo a leitura, algumas estratégias devem ser levadas em consideração. Solé (1998) explica que as estratégias de leitura são procedimentos envolvendo objetivos a realizar, o planejamento para realizá-los e uma avaliação que permita mudanças, se necessário, ocorrendo em três momentos: antes da leitura, durante a leitura e depois da leitura, permitindo a compreensão do texto.

Essas estratégias, que preveem o desenvolvimento de leitores autônomos e, por isso, capazes de compreender textos de diferentes estruturas e objetivos, permeiam a compreensão daquilo que está explícito no texto, bem como do que se encontra nas entrelinhas; a ativação dos conhecimentos prévios capazes de trazer significados e facilitar o entendimento; a valorização daquilo que realmente é importante durante a leitura; a elaboração de hipóteses por meio das previsões e inferências ao longo do texto, atividade esta que se inicia desde a observação do título e das ilustrações da capa, entre outras ações, compreendendo, como explica Solé (1998, pg. 120) que "não existem receitas exatas [...], pois as situações de leitura podem ser muito variadas".

Complementando nossa abordagem, Girotto e Silva (2010) nos dizem que

Pedir para as crianças visualizarem, fazerem conexões e contarem o imaginado-penado-refletido durante a leitura, leva-as a um aumento de interesse e envolvimento. Desse ponto de vista, o ensino das estratégias utilizadas para ler incentiva as crianças a pensar mais cuidadosamente sobre a leitura. (GIROTTO E SILVA, 2010, p. 57)

As autoras salientam ainda que "é importante considerar que o ensino das estratégias de compreensão pode e deve ser implementado em qualquer contexto de sala de aula com materiais diversos" (GIROTTO E SILVA, 2010, pg. 60), ressaltam também a importância da ativação do conhecimento prévio, onde ficariam evidentes todas as demais estratégias: a previsão, a interlocução, o questionamento e a indagação.

Pensando nestes momentos, no dia anterior à leitura do livro ou mesmo momentos antes da leitura "deixar no ar" o título da obra, indagando sobre o que as crianças acreditam que ela possa tratar, pedindo para que escrevam suas expectativas.

No momento da leitura do livro, instigá-los novamente sobre suas expectativas, levantando informações a respeito dos assuntos abordados nos livros e, posteriormente, com a observação da capa do livro, o que eles esperam da história que será lida. Iniciar a leitura do livro sempre unindo o texto verbal ao texto não verbal, de maneira a permitir uma leitura completa, levantando hipóteses sobre os acontecimentos do livro e possíveis acontecimentos parecidos que os educandos já tenham vivenciado. 
Esses são apenas alguns exemplos de ações que possibilitam o desenvolvimento das estratégias de leitura de maneira a deixar as crianças interessadas pelo ato de ler, ativando seus conhecimentos prévios e permitindo que o texto tenha significado em suas vidas.

Por vezes, ao realizar essa atividade, não exista um exemplar do livro para cada criança e, por isso, a leitura tenha que ser feita pelo professor, em um círculo que permita a visualização do livro em detalhes. Lembramos que é importante explicar às crianças que essas atitudes realizadas na leitura coletiva do livro, devem ser repetidas em todas as leituras, mesmo as individuais, de maneira que assumam como um hábito as estratégias de leitura e sejam capazes de ler, resumir, solicitar esclarecimentos e prever o que está por vir, habilidades adequadas à compreensão de variados tipos textuais.

Girotto e Silva (2010) explicam que as estratégias de leitura percorrem diferentes espaços que devem ampliar-se, partindo da casa das crianças para o bairro, a cidade, até chegar a assuntos mais distantes de seu cotidiano. Mais uma vez chamam a atenção para o uso das experiências pessoais e coletivas para a construção dos significados, dizendo que:

O conhecimento prévio que as crianças trazem para a leitura sustenta todos os aspetos da aprendizagem e entendimento. Se os leitores não tem nada para articularem à nova informação, é bem difícil que construam significados [...] fazer conexões com as experiências pessoas facilita o entendimento. As vivências e conhecimentos prévios dos leitores abastecem as conexões que fazem (GIROTTO E SILVA, 2010, pg. 66 e 67).

Ao pensarmos no uso de livros de literatura infantil para desenvolver assuntos pertinentes ao nosso cotidiano, enfrentamos certa resistência por parte de vários pesquisadores da área, por não acreditarem que os livros devam servir de base para o desenvolvimento de assuntos variados, por fugir do sentido para qual o livro foi criado, fazendo com que a criança passe a vê-lo de maneira distorcida. Contudo, lembramos que nossa intenção não é realizar a leitura do livro de maneira sistemática e apenas chamando atenção para o fato que pretendemos trabalhar, mas realizar a leitura de forma prazerosa e lúdica e introduzir os assuntos sem ferir a intencionalidade real do livro infantil, diferente do que ocorre com o livro paradidático, que já é criado com um fim objetivo.

De forma breve, compreendemos que "o texto literário é aquele que não possui compromisso com o leitor, com os textos paradidáticos ou com o texto didático. Ele é estética, criação, imaginário, fantasia, pensamento e atitude" (ALMEIDA, 2008, p.51). Os livros paradidáticos, por sua vez, possuem outro objetivo, como descreve Paiva e Oliveira: 
Os livros paradidáticos são muito utilizados nas escolas por apresentarem características utilitaristas, ou seja, com intencionalidade determinada vinculada à escola. Neste sentido, o livro paradidático extingue a experiência estética e trata seus leitores de forma homogênea, o que os distingue dos livros literários. Os livros paradidáticos apresentam uma metodologia determinada de trabalho. Pretendem, com este tipo de trabalho, que os leitores cheguem a uma única interpretação do texto lido. Geralmente, contém fichas de leituras, elaboradas por autores ou especialistas para serem preenchidas pelos leitores. (PAIVA e OLIVEIRA, 2010, pg. 31)

Hunt (2010, pg. 129) diz que "devemos tomar cuidado para não nos envolvermos nos argumentos esnobes sobre qual livro é melhor, pois isso depende do uso que se quer dar à obra". Complementando seu pensamento, o autor explica que

[...] no lugar de dizer "melhor/pior", ou "adequado/inadequado", a crítica seria empregada com mais proveito ao dizer: "Esse texto tem determinado potencial para interação, determinadas possibilidades de significado". Na pior das hipóteses, escaparíamos da confusão atual de "bom" e "bom para", que leva a escrita preguiçosa a ser louvada - uma vez que condená-la seria esnobismo -, e as crianças a serem expostas a textos indiferentes, pois os adultos não tem meios de distingui-los.(HUNT, 2010, pg. 130)

Ainda refletindo sobre a escolarização da literatura infantil, Soares (2011) explica que é interessante observar que o desenvolvimento da literatura infantil no Brasil acompanha o desenvolvimento da educação escolar, tendo seu fortalecimento elencado ao aumento do número de vagas nas escolas brasileiras.

Somamos a esse pensamento o que afirma Coelho (2000) ao dizer que a partir dos anos 70 a leitura do livro infantil transcendeu o simples divertimento e passou a ser vista como "um fecundo instrumento de formação humana, ética, estética, política etc.", sendo uma ferramenta importante para "formar ou transformar mentes". Soares (2011) então afirma que "não há como ter escola sem ter a escolarização dos conhecimentos, saberes, artes" e completa dizendo que

Não há como evitar que a literatura, qualquer literatura, não só a literatura infantil e juvenil, ao se tornar "saber escolar", se escolarize, e não se pode atribuir, em tese, como dito anteriormente, conotação pejorativa a essa escolarização, inevitável e necessária; não se pode criticá-la ou negá-la, porque isso significaria negar a própria escola." (SOARES, 2011, pg 21)

Mas não podemos negar que uma escolarização imprópria pode deformar o texto literário, atribuindo-Ihe um sentido negativo, como aponta a própria autora. Longe da nossa intenção, uma vez que buscamos usufruir de todos os aspectos da leitura, deixando-a fluir de maneira prazerosa, durante a decodificação do texto, o ato de ler para o outro, de contar a história ou durante o ato 
de ler como momento individual do ser. Nosso propósito é mostrar que nos momentos anteriores à leitura e após a leitura, ao resgatarmos os conhecimentos prévios, desencadearmos conexões, sejam texto-texto, texto-leitor ou texto-mundo, sejamos capazes de permitir uma reflexão proveitosa, transmitindo noções de responsabilidade ambiental e de cidadania, capazes de se fixar como valores a serem transportados para a vida adulta e disseminados em seu entorno. Dessa forma, vemos como importante o momento da leitura literária, mas apresentamos intencionalidades para os momentos antes e depois leitura.

\section{CONCLUSÃO}

De maneira geral, a intenção deste trabalho é materializar a possibilidade de assimilação de conceitos e o desenvolvimento de atitudes ambientalmente corretas de maneira lúdica, própria dos livros infantis, não esgotando as possibilidades literárias das obras, mas acrescentando novos conteúdos a partir das leituras e indagações que as crianças são levadas a fazer a partir do desenvolvimento da autonomia e do pensamento crítico.

Por outro lado, os trabalhos manuais são fundamentais para a apreensão dos conteúdos, uma vez que as crianças acabam agindo como disseminadoras ao apresentarem seus trabalhos para os amigos e familiares, explicando o que aprenderam de forma a fixar os conhecimentos.

\section{REFERÊNCIAS}

ALMEIDA, G. P. Práticas de leituras: Curitiba: Pró-Infantil, 2008.

CARVALHO, B. V. Uma avenida na floresta. São Paulo: Melhoramentos, 1990.

CARVALHO, I. C. M. Educação Ambiental: a formação do sujeito ecológico. 2a edição. São Paulo: Cortez, 2006.

COELHO, N. N. Literatura infantil: teoria, análise, didática. São Paulo: Moderna, 2000.

DOMENICHELLI, G. O resgate da tartaruga. São Paulo: Panda Books, 2014.

GIROTTO, C.; SOUZA, R. J. Estratégias de leitura: para ensinar alunos a compreender o que leem. In: SOUZA, R. J.; GIROTTO, C. G. G. S.; ARENA, D. B. ; MENIN, A. M. Ler e compreender: estratégias de leitura. Campinas, São Paulo: Mercado das Letras, 2010.

HUNT, P. Crítica, teoria e literatura infantil. Tradução de Cid Knipel. São Paulo: Cosac Naify, 2010.

LAGO, A. A festa no céu: um conto no nosso folclore. São Paulo: melhoramentos, 2005.

PAIVA, S. C. F. e OLIVEIRA, A. A. A literatura infantil o processo de formação do leitor. Cadernos da Pedagogia, São Carlos, ano 4, v. 4, n. 7, jan.-jun. 2010. p. 22-36. Disponível em: 
<http://www.cadernosdapedagogia.ufscar.br/index.php/cp/article/viewFile/175/101>. Acesso em: 10 jul. 2015.

SOARES, M. A escolarização da literatura infantil e juvenil. In: EVANGELISTA, A. A. M.; BRANDÃO, H. M. B.; MACHADO, M. Z. V. (organizadoras). Escolarização da leitura literária. 2a ed., 3a reimp. Belo Horizonte: Autêntica, 2011.

SOLÉ, I. Estratégias de leitura. Porto Alegre: Artmed, 1998. 